Received: 2015.09 .07 Accepted: 2015.11.16 Published: 2016.03.22

Authors' Contribution: Study Design A Data Collection B Statistical Analysis C Data Interpretation D Manuscript Preparation E Literature Search F Funds Collection G

\section{Tacrolimus Concentration/Dose Ratio is Associated with Renal Function After Liver Transplantation}

\author{
ABCE 1 Gerold Thölking \\ BC 1 Lea Siats \\ BC 1 Christian Fortmann \\ CE 2 Raphael Koch \\ BD 3 Anna Hüsing \\ DE 3 Vito R. Cicinnati \\ BCE 1 Hans Ulrich Gerth \\ CD 4 Heiner H. Wolters \\ BD 4 Christoph Anthoni \\ DE 1 Hermann Pavenstädt \\ CE 1 Barbara Suwelack \\ DE 3 Hartmut H. Schmidt \\ DEF 3 lyad Kabar
}

1 Department of Medicine D, Division of General Internal Medicine, Nephrology and Rheumatology, University Hospital Münster, Münster, Germany

2 Institute of Biostatistics and Clinical Research, University of Münster, Münster, Germany

3 Department of Transplant Medicine, University Hospital of Münster, Münster, Germany

4 Department of General Surgery, University Hospital of Münster, Münster, Germany
Corresponding Author: Source of support:

Background: The calcineurin inhibitor (CNI) tacrolimus (Tac) is an effective immunosuppressant used after liver transplantation (LTX), but is often associated with CNI nephrotoxicity. Currently, there is no simple clinical predictor for CNI nephrotoxicity after LTx. We hypothesized that the Tac metabolism rate - defined as the blood concentration normalized by its daily dose (the C/D ratio) - is associated with post-LTx renal impairment.

Material/Methods: We analyzed the relationship between the C/D ratio and post-transplant renal function in 179 patients who underwent LTx between 2000 and 2012 and were initially immunosuppressed with Tac, mycophenolate mofetil, and prednisolone. Six months after LTx, 115 patients were categorized into 1 of 2 groups based on their Tac C/D ratio $(<1.09$ or $\geq 1.09)$ : fast $(n=58)$ or slow $(n=57)$ metabolizers. The renal function was determined 36 months after LTx using the estimated glomerular filtration rate (eGFR) as described by Cockcroft and Gault.

Results: At the time of LTx there was no statistically significant difference between the eGFR of fast and slow metabolizers. Six months $(P=0.016), 12$ months $(P=0.001)$, and 36 months $(P=0.018)$ after $L T x$, fast Tac metabolizers had significantly more impaired renal function than slow metabolizers. Because of a presumption of CNI nephrotoxicity, $32.8 \%$ of fast metabolizers and $14.0 \%$ of slow metabolizers were switched from Tac to other immunosuppressants $(\mathrm{P}=0.027)$.

Conclusions: In this study, the Tac metabolism rate appears to influence renal function after LTX, suggesting that a C/D ratio of $<1.09$ is associated with increased CNI nephrotoxicity in LTx recipients.

MeSH Keywords: $\quad$ Calcineurin • Liver Transplantation • Metabolism • Renal Insufficiency • Tacrolimus

Full-text PDF: http://www.annalsoftransplantation.com/abstract/index/idArt/895898

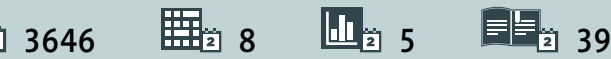




\section{Background}

The calcineurin inhibitor (CNI) tacrolimus (Tac) is a standard immunosuppressant used after liver transplantation (LTX). The incidence of acute liver rejection is lower with Tac than with cyclosporin A [1], but Tac also exhibits CNI nephrotoxicity [2,3]. The extent of nephrotoxicity is reportedly strongly associated with high trough blood CNI concentrations [4]. However, nephrotoxic adverse effects may also occur with regimens that aim to achieve low trough Tac concentrations (target 4-6 ng/mL) [5].

Tacrolimus metabolism depends on several individual clinical and genetic factors. Demographic characteristics such as sex and age have been identified as having an influence on Tac metabolism after kidney transplantation $[6,7]$. Furthermore, several drug interactions with the cytochrome P450 CYP3A enzyme system lead to changes in Tac blood concentrations [8], including corticosteroids [9]. The Tac dose requirement is influenced by uptake from the lower intestine [10], and episodes of severe diarrhea are known to increase Tac blood concentration [11]. There has also been a recent focus on the influence of the expression of different cytochrome P450 (CYP450) subtypes in the renal tubules on the incidence of $\mathrm{CNI}$ nephrotoxicity [12]. The metabolism of Tac is mainly controlled by CYP3A4 and CYP3A5 in the liver [13]. CYP3A5*1-expressors have been characterized as fast Tac metabolizers, while slow metabolizers mostly express CYP3A5 $3[14,15]$. After LTx, there is a switch from the CYP450 system of the native liver to that of the allograft. Thus, there are 2 different CYP3A-systems at work in LTx recipients, meaning that it may be very difficult to determine the subsequent Tac requirement by genetic pretesting before LTx [16].

Currently, there is no simple clinical tool available that can predict the onset of CNI nephrotoxicity in LTx recipients. Recently, we showed that the Tac metabolism rate, expressed as the blood concentration normalized by the dose (C/D ratio), has an impact on kidney function after renal transplantation (RTX) [17]. The most likely reason for impaired renal function in patients exhibiting a low C/D ratio (fast Tac metabolizers) is thought to be CNI nephrotoxicity. It was hypothesized that fast metabolizers might suffer from overexposure and related over-immunosuppression or toxicity, at least at some time during the day. The Tac C/D ratio is an established means of determining its rate of metabolism [18]. Several other research groups have used the C/D ratio adjusted for patient weight, but there are many more clinical and genetic factors that influence the Tac dose requirement, and recent studies have shown the clinical utility of using the C/D ratio without adjusting for weight $[17,19]$.

We hypothesized that the Tac metabolism rate, expressed as the $C / D$ ratio, is associated with renal function in LTx recipients.

\section{Material and Methods}

\section{Study population and clinical data}

Figure 1 illustrates the study enrollment. This retrospective study included patients who had undergone cadaveric liver transplantation at the University Hospital of Münster between January 2000 and March 2012 and took Tac for at least 6 months thereafter. All included patients were started on an immunosuppressant regimen with Tac (Prograf), mycophenolate mofetil (CellCept), and prednisolone (Soludecortin $\mathrm{H} /$ Decortin H). Tacrolimus was started at a dose of $0.1 \mathrm{mg} / \mathrm{kg}$ twice daily with a target trough concentration of $7-12 \mathrm{ng} / \mathrm{mL}$ during the first month, $6-10 \mathrm{ng} / \mathrm{mL}$ from months 2 to 3 , and 4-8 $\mathrm{ng} / \mathrm{mL}$ thereafter. Mycophenolate mofetil was started at a dose of $1 \mathrm{~g}$ twice daily and adapted as necessary to counter adverse effects such as leukopenia, diarrhea, and infection. Prednisolone was started at a dose of $250 \mathrm{mg}$ once daily intravenously before and immediately after transplantation and for the following 2 days; the dose was reduced to $100 \mathrm{mg}$ per day for the next 3 days, then tapered by $20 \mathrm{mg}$ per day. A dose of $20 \mathrm{mg}$ per day was maintained until the end of the first month after transplant, and then further tapered stepwise

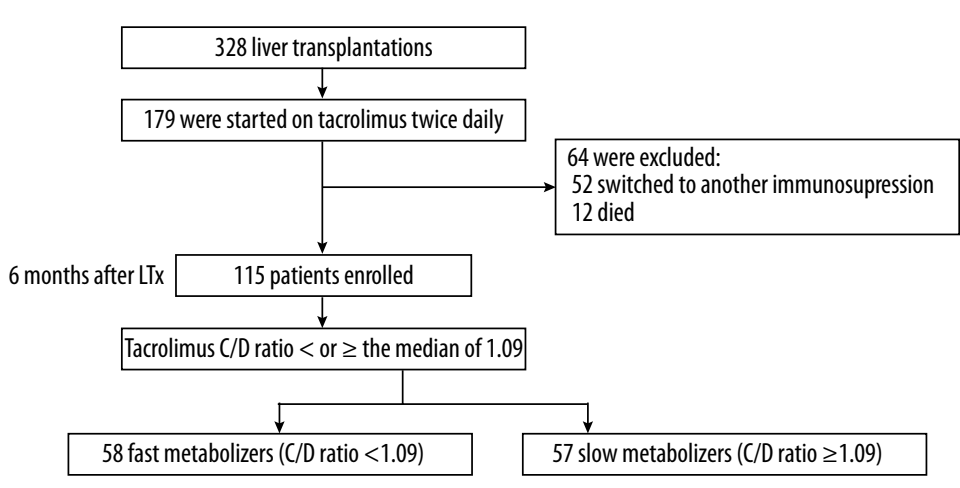

Figure 1. Enrollment and group classification. We performed 328 liver transplantations (LTX) on 280 patients. The latest LTX of 115 LTx patients were included in the analysis. These patients were divided into fast and slow metabolizers according to their tacrolimus concentration/dose (C/D) ratio $\left(\mathrm{ng} / \mathrm{mL}^{*} 1 / \mathrm{mg}\right)$ at 6 months after LTx. Data on renal function, switch of immunosuppression, and serious adverse events were analyzed at 36-month follow-up. 
by $5 \mathrm{mg}$. In most cases, prednisolone had been discontinued within 6-12 months after LTX.

The demographic characteristics of recipients were collected at the time of LTx, including sex, age, body weight, and height. The body mass index (BMI) was calculated by dividing the body weight in kilograms by the square of the height in meters. We also recorded the blood type of donor and recipient, number of previous transplantations, and cold and warm ischemia times. The results of laboratory investigations, such as serum bilirubin and alanine transaminase (ALT) concentrations, and the international normalized ratio (INR), were collected at LTx and after defined time points. All changes in the immunosuppressant regimen were documented. Data on loss of transplant function and the death of patients were taken from clinical records. Follow-up data were collected retrospectively until September 2012, by which time all patients had undergone at least a 6 months of follow-up after LTx.

All patients received Tac for at least 6 months after transplantation. Patients who were given a different $\mathrm{CNI}$, such as cyclosporin A (Sandimmune), an extended-release formulation of Tac (Advagraf), or a drug known to interfere with Tac metabolism, were excluded from the analysis. We also excluded patients under the age of 16 years. Furthermore, we excluded patients who had undergone combined organ transplantation (e.g., pancreas, kidney, and heart) due to the differing immunosuppressant regimens used after transplantation, those who discontinued Tac or were switched to another immunosuppressant, lost liver function, died, or were lost to follow-up.

All data were collected retrospectively. Data of all patients were anonymized and de-identified prior to analysis. Our study was approved by the local ethics committee (Ethik Kommission der Ärtzekammer Westfalen-Lippe und der Medizinischen Fakultät der Westfälischen Wilhelms-Universität, No. 2015-167-s-n). Written informed consent was given by all participants at the time of transplantation for recording their clinical data and use in anonymized analysis.

\section{Clinical chemistry}

The concentrations of creatinine (enzymatic assay; CreatininePap, Roche Diagnostics, Mannheim, Germany) and Tac were measured from whole blood samples using an automated Tac assay (TACR, Dimension Clinical Chemistry System, Siemens Healthcare Diagnostic GmbH, Eschborn, Germany). The Tac metabolism rate was determined by dividing the drug blood trough concentration $(C)$ by the corresponding daily Tac dose (D). The C/D ratio was documented at 1 month, 3 months, and 6 months after transplantation:

$$
\text { C/D ratio }(\mathrm{ng} / \mathrm{mL} \times 1 / \mathrm{mg})=\frac{\text { blood Tac trough concentration }(\mathrm{ng} / \mathrm{mL})}{\text { daily Tac dose }(\mathrm{mg})}
$$

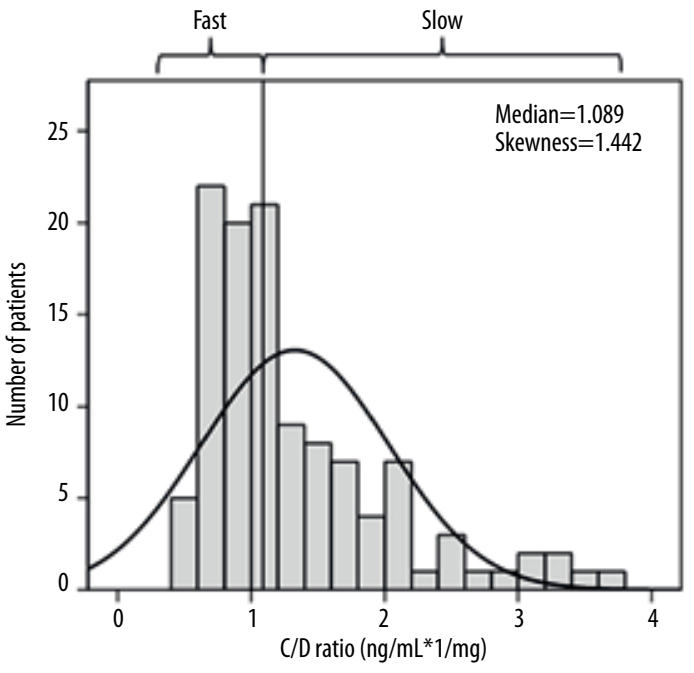

Figure 2. Histogram of the distribution of the tacrolimus blood concentration normalized by its daily dose (the $\mathrm{C} / \mathrm{D}$ ratio, $\left.\mathrm{ng} / \mathrm{mL}^{*} 1 / \mathrm{mg}\right)$. C/D ratio was distributed asymmetrically in the cohort of patients who had undergone LTx, allowing categorization into 1 of 2 groups: fast or slow metabolizers.

\section{Definition of fast and slow metabolizer groups}

Because of potential interactions between Tac and prednisolone, the C/D ratio measured 6 months after LTx was used to determine the postoperative Tac metabolism rate, by which time prednisolone was being given at a low dose or had already been discontinued. Because of a skewed distribution of the $C / D$ ratio values (Figure 2), non-parametric methods were used for statistical analysis. The median C/D ratio of 1.09 was used to divide patients into 2 groups. Patients with a C/D ratio $<1.09$ were defined as fast metabolizers and those with a ratio $\geq 1.09$ were defined as slow metabolizers (Figure 1 ).

\section{Renal function}

Renal function was determined by calculating the estimated glomerular filtration rate (eGFR) at the time of LTx, and at 1 month, 3 months, 6 months, 12 months, and 36 months after transplantation. Primarily due to mean eGFR $>60 \mathrm{~mL} / \mathrm{min}$, the Cockcroft-Gault (CG) equation was used [20]. In a further step, eGFR values obtained by the Modification of Diet in Renal Disease group (MDRD) formula [21] were used to confirm the results.

\section{Statistical analysis}

Statistical analyses were performed using IBM SPSS Statistics 22 for Windows (IBM Corporation, Somers, NY, USA) and SAS 
software, version 9.4 of the SAS System for Windows (SAS Institute, Cary, NC, USA). Inferential statistics were intended to be exploratory instead of confirmatory, and were interpreted accordingly, meaning that P-values were only used to generate new hypotheses. Thus, neither a global significance level nor local levels were determined, and no adjustment for multiplicity was made. P-values represent a metric measure of evidence against the respective null hypothesis, and were considered as statistically significant if $\mathrm{P} \leq 0.05$.

The primary target parameter was eGFR ( $\mathrm{mL} / \mathrm{min})$. Standard univariate statistical analyses were used to describe demographic and clinical parameters. Categorical variables are shown as absolute and relative frequencies. To quantify evidence of differences between the 2 metabolism groups (fast and slow), Fisher's exact tests were used for categorical variables. Continuous variables assumed to be normally distributed are presented as the mean \pm standard deviation. Non-normally distributed metric variables are reported as median (minimum, maximum). Due to their distributional properties, pairwise comparisons between the 2 Tac groups were performed using 2-sided t-tests for independent groups or the MannWhitney $U$ test if applicable.

Multivariable analyses were performed for longitudinal data. The aim was to estimate the covariable-adjusted effects on eGFR. To account for missing values (treated as missing at random) and dependencies between repeated measurements, linear mixed models were fitted. The dependent variable was eGFR ( $\mathrm{mL} / \mathrm{min})$. Fixed factors were the main effects of age at LTx (years), sex of the recipient (female, male), weight $(\mathrm{kg})$, BMI $\left(\mathrm{kg} / \mathrm{m}^{2}\right)$, hepatitis C virus (HCV) antibody status of the recipient (positive, negative), point in time (at LTX, 1 month, 3 months, 6 months, 12 months, and 36 months after LTx), and the Tac metabolism group (fast, slow), as well as the interaction effect (Tac metabolism group* point in time). The interaction term represents the slopes of the Tac metabolism groups over time, or rather the difference in the longitudinal change in eGFR between the groups. The model included a random intercept for each patient and a first-order antedependence covariance structure (ANTE) (1) for the residuals accounting for the dependencies between the longitudinal measurements

Table 1. Patient characteristics.

\begin{tabular}{|c|c|c|c|}
\hline & $\begin{array}{l}\text { Fast metabolizers } \\
\qquad(n=58)\end{array}$ & $\begin{array}{l}\text { Slow metabolizers } \\
\qquad(n=57)\end{array}$ & P-value \\
\hline Age (years) & $51.1 \pm 11.8$ & $50.3 \pm 12.9$ & $0.728^{*}$ \\
\hline BMI $\left(\mathrm{kg} / \mathrm{m}^{2}\right)$ & $24.4 \pm 4.2$ & $25.7 \pm 4.6$ & $0.116^{*}$ \\
\hline Height (m) & $1.73 \pm 8.9$ & $1.74 \pm 9.5$ & $0.286^{*}$ \\
\hline Weight (kg) & $73.7 \pm 14.8$ & $78.0 \pm 17.7$ & $0.166^{*}$ \\
\hline $\operatorname{Sex}(m / f)$ & $33(56.9 \%) / 25$ (43.1\%) & $44(77.8 \%) / 13$ (22.8\%) & $0.029^{* *}$ \\
\hline Donor age (years) & $48.0 \pm 16.3$ & $51.8 \pm 14.8$ & $0.187^{*}$ \\
\hline Donor sex $(m / f)$ & 35 (60.3\%)/23 (39.7\%) & 38 (66.7\%)/19 (33.3\%) & $0.562^{\star *}$ \\
\hline Donor weight (kg) & $78.7 \pm 14.4$ & $79.7 \pm 15.5$ & $0.704^{*}$ \\
\hline Donor height $(\mathrm{m})$ & $1.75 \pm 0.09$ & $1.73 \pm 0.09$ & $0.169^{*}$ \\
\hline Donor BMI (kg/m²) & $25.6 \pm 4.8$ & $26.5 \pm 4.1$ & $0.270^{*}$ \\
\hline CIT (h) & $10.4 \pm 2.8$ & $10.2 \pm 2.3$ & $0.593^{*}$ \\
\hline WIT (min) & $44.0 \pm 9.2$ & $44.4 \pm 16.3$ & $0.855^{\star}$ \\
\hline mean SE-MELD & 21.6 & 18.4 & $0.124^{*}$ \\
\hline \multicolumn{4}{|l|}{ Number of LTx } \\
\hline One & $52(89.7 \%)$ & $54(94.7 \%)$ & \\
\hline Two & $6(10.3 \%)$ & $2(3.5 \%)$ & $0.272^{\star *}$ \\
\hline Three & 0 & $1(1.8 \%)$ & \\
\hline
\end{tabular}

BMI - body mass index; CIT - cold ischemic time; WIT - warm ischemic time; SE-MELD - Standard Exceptions-Model for End-stage Liver Disease; LTx - liver transplantation; * P-values from t-tests; ${ }^{* *}$ P-values from Fisher's exact tests. 
Table 2. Causes for LTX and comorbidities.

\begin{tabular}{|c|c|c|c|}
\hline & $\begin{array}{l}\text { Fast metabolizers } \\
\qquad(n=58)\end{array}$ & $\begin{array}{l}\text { Slow metabolizers } \\
\qquad(n=57)\end{array}$ & P-value \\
\hline \multicolumn{4}{|l|}{ Causes for LTX } \\
\hline Chronic hepatitis C & 3 & 5 & - \\
\hline Chronic hepatitis B & 1 & 3 & - \\
\hline Alpha-1 antitrypsin deficiency & - & 1 & - \\
\hline Alcoholic liver disease & 16 & 13 & 0.559 \\
\hline Hepatoblastoma & - & 1 & - \\
\hline Hepatocellular carcinoma & 9 & 11 & 0.597 \\
\hline Cryptogenic liver cirrhosis & 4 & 2 & - \\
\hline Nutritiv toxic liver cirrhosis & - & 1 & - \\
\hline Budd-Chiari-syndrome & 1 & - & - \\
\hline Amyloidosis & 1 & 3 & - \\
\hline Wilson's disease & - & 1 & - \\
\hline Primary biliary cirrhosis & - & 4 & 0.040 \\
\hline Primary sclerosing cholangitis & 4 & 5 & - \\
\hline Autoimmune hepatitis & 5 & - & 0.023 \\
\hline Polycystic liver disease & 2 & - & - \\
\hline Hemochromatosis & - & 1 & - \\
\hline Steatohepatits & 1 & - & - \\
\hline Drug-induced acute liver failure & 1 & - & - \\
\hline Acute liver failure (toxic, unknown) & 4 & 2 & - \\
\hline LTx failure & 2 & - & - \\
\hline Posthepatic liver cirrhosis & 4 & 3 & - \\
\hline Traumatic liver rupture & - & 1 & - \\
\hline \multicolumn{4}{|l|}{ Comorbidities at LTX } \\
\hline Diabetes mellitus & $20(34.5 \%)$ & $20(35.1 \%)$ & 0.946 \\
\hline Arterial hypertension & $25(43.1 \%)$ & $22(38.6 \%)$ & 0.627 \\
\hline Hepatorenal syndrome & $14(24.1 \%)$ & $15(26.3 \%)$ & 0.788 \\
\hline
\end{tabular}

LTx - liver transplantation; P-values from t-tests.

of each patient. Pairwise comparisons between the groups at each point in time were estimated within the multivariable linear mixed model. Results are reported as regression coefficients and corresponding $95 \%$ confidence intervals $(95 \% \mathrm{CI})$, or global P-values of the F-test.

\section{Results}

\section{Study population}

Between January 2000 and March 2012, 328 liver transplants were performed on 280 patients (Figure 1). Of these, 179 received an initial immunosuppressant regime with Tac, mycophenolate mofetil, and prednisolone. Table 1 shows the 
Table 3. Renal function (eGFR in $\mathrm{mL} / \mathrm{min}$ ).

\begin{tabular}{|c|c|c|c|c|c|c|c|c|c|}
\hline $\begin{array}{l}\text { Time } \\
\text { point }\end{array}$ & $\begin{array}{c}\text { Tac metabolism } \\
\text { group }\end{array}$ & $\mathbf{N}$ & Mean \pm SD & $10 \% \mathrm{q}$ & $25 \% \mathrm{q}$ & $\begin{array}{c}\text { Median } \\
(\min -\max )\end{array}$ & $75 \% q$. & $90 \%$ q. & Skewness \\
\hline \multirow{2}{*}{ at LTx } & Fast & 58 & $80 \pm 38$ & 35 & 50 & $80(13-185)$ & 95 & 137 & 0.66 \\
\hline & Slow & 57 & $91 \pm 40$ & 33 & 66 & 91 (19-209) & 112 & 142 & 0.40 \\
\hline \multirow{2}{*}{1 month } & Fast & 58 & $82 \pm 37$ & 33 & 58 & 79 (18-192) & 103 & 128 & 0.78 \\
\hline & Slow & 57 & $98 \pm 51$ & 42 & 68 & $91(25-253)$ & 111 & 197 & 1.24 \\
\hline \multirow{2}{*}{3 months } & Fast & 58 & $82 \pm 33$ & 48 & 59 & $73(18-201)$ & 99 & 117 & 1.23 \\
\hline & Slow & 57 & $93 \pm 38$ & 47 & 65 & $89(29-194)$ & 112 & 141 & 0.63 \\
\hline \multirow{2}{*}{6 months } & Fast & 58 & $74 \pm 31$ & 42 & 49 & $71(14-166)$ & 93 & 114 & 0.78 \\
\hline & Slow & 57 & $91 \pm 36$ & 44 & 65 & $90(30-178)$ & 114 & 141 & 0.35 \\
\hline \multirow{2}{*}{12 months } & Fast & 45 & $69 \pm 31$ & 37 & 52 & $62(10-208)$ & 88 & 97 & 1.92 \\
\hline & Slow & 41 & $89 \pm 37$ & 43 & 71 & $84(27-188)$ & 106 & 138 & 0.65 \\
\hline \multirow{2}{*}{36 months } & Fast & 26 & $79 \pm 37$ & 37 & 57 & 77 (34-206) & 99 & 117 & 1.55 \\
\hline & Slow & 18 & $87 \pm 33$ & 44 & 69 & 85 (44-177) & 103 & 125 & 1.08 \\
\hline
\end{tabular}

All eGFR values were estimated by the Cockcroft-Gault equation; SD - standart deviation; q. - quantil.

descriptive statistics of the 115 LTx recipients who fulfilled the study inclusion criteria by remaining on Tac for at least 6 months post-transplant. The C/D ratio 6 months after LTx was used to classify the patients into 2 groups; values showed a skewed distribution (Figure 2 ). The median C/D ratio was 1.09 $\mathrm{ng} / \mathrm{mL}^{*} 1 / \mathrm{mg}\left(0.46-3.60 \mathrm{ng} / \mathrm{mL}^{*} 1 / \mathrm{mg}\right)$. The 115 patients included in the analysis were thus categorized into 1 of 2 groups: fast metabolizers $(n=58, C / D$ ratio $<1.09)$ and slow metabolizers $(n=57, C / D$ ratio $\geq 1.09)$.

The patients' mean age was $50.7 \pm 12.3$ years (range 16-68 years), and 73 (63.5\%) were male. The group of slow metabolizers contained significantly more male patients compared to the fast metabolizers group (Table 1). At the time of LTx, none of the patients was on dialysis. During the 36 months follow-up, 3 fast metabolizers suffered from end-stage renal disease and went on dialysis. Causes for LTx and comorbidities are displayed in Table 2. The main reason for LTx was alcoholic liver cirrhosis in both groups. The group of slow metabolizers included significantly more patients with primary biliary cirrhosis $(P=0.040)$, and the fast metabolizers group had significantly more cases of autoimmune hepatitis $(P=0.023)$. Further underlying diseases and relevant comorbidities did not differ significantly between the 2 groups.

\section{Influences on renal function}

Descriptive statistics (univariate analysis) of renal function are shown in Table 3. Linear mixed models were fitted to identify independent factors with statistically significant influences on renal function during the follow-up period of 36 months (Table 4, all eGFR values obtained by the CG equation [20]). The baseline covariate of age at LTx was significantly influential $(P \leq 0.05)$. Furthermore, the main effects in the Tac metabolism group and time point showed a significant influence on renal function (Table 4). Figure 3 illustrates mean estimates of the eGFR values and corresponding $95 \%$ confidence intervals from the multivariable linear mixed model. At the time of LTx, and at 1 month and 3 months after LTx, the eGFR values did not differ significantly. At 6 months, 12 months, and 36 months after LTx, fast Tac metabolizers exhibited noticeably more impaired renal function than slow metabolizers. Interestingly, fast metabolizers showed a continuous reduction in eGFR during 12-month follow-up (Figure 3). A slight recovery in eGFR in fast metabolizers between 12 and 36 months and in slow metabolizers between 6 and 36 months might have been caused by a substantial drop-out rate (according to the exclusion criteria of this study: switch of immunosuppression and death). The slopes of fast and slow metabolizers, indicating the change over time, were not significantly different. Although the pairwise comparison (linear mixed model) of eGFR values 12 months after LTx revealed a $16.5 \mathrm{ml} / \mathrm{min}$ lower eGFR value in the group of fast metabolizers (Table 4), the scatterplot showed no clear correlation between the C/D ratio and eGFR values 12 months after LTx ( $r=0.311$; Figure 4). Notably, only 3 fast metabolizers, but 13 slow metabolizers, showed an eGFR $>100 \mathrm{ml} / \mathrm{min}$ at 12 months after LTx (Figure 4). 
Table 4. Renal function (linear mixed model, Cockcroft-Gault equation).

\begin{tabular}{|c|c|c|c|c|}
\hline \multirow[b]{2}{*}{ Independent variable } & \multicolumn{3}{|c|}{ Model-based influence estimates on eGFR ( $\mathrm{ml} / \mathrm{min}$ ) } & \multirow[b]{2}{*}{ P-value } \\
\hline & Estimate & $\begin{array}{l}\text { Lower } 95 \% \\
\text { confidence limit }\end{array}$ & $\begin{array}{c}\text { Upper } 95 \% \\
\text { confidence limit }\end{array}$ & \\
\hline \multicolumn{5}{|l|}{ Main effects } \\
\hline Sex (f vs. m) & -7.7 & -20.9 & 5.4 & 0.249 \\
\hline HCV status (pos. vs. neg.) & -11.7 & -23.8 & -0.3 & 0.107 \\
\hline BMI (per kg/m²) & 0.1 & -2.4 & 2.6 & 0.927 \\
\hline Weight at LTx (per kg) & 0.7 & -0.1 & 1.4 & 0.084 \\
\hline Age at LTx (per year) & -1.4 & -1.8 & -1.1 & $<0.001$ \\
\hline Time point (categorical) & - & - & - & 0.026 \\
\hline Tac metabolism group (slow vs. fast) & - & - & - & 0.014 \\
\hline \multicolumn{5}{|l|}{ Interaction (slopes) } \\
\hline Tac metabolism group * time point & - & - & - & 0.188 \\
\hline \multicolumn{5}{|l|}{$\begin{array}{l}\text { Pairwise comparison of Tac metabolism } \\
\text { group (slow vs. fast) }\end{array}$} \\
\hline At LTx & 3.0 & -9.8 & 15.7 & 0.649 \\
\hline At 1 month & 9.0 & -5.2 & 23.2 & 0.211 \\
\hline At 3 months & 8.4 & -0.9 & 17.6 & 0.078 \\
\hline At 6 months & 11.4 & 2.0 & 20.7 & 0.017 \\
\hline At 12 months & 16.5 & 7.0 & 26.1 & 0.001 \\
\hline At 36 months & 13.0 & 2.2 & 23.8 & 0.018 \\
\hline
\end{tabular}

Selected results from the linear mixed model. Regression coefficient estimates, contrast estimates and $95 \%$ confidence limits of fixed effects on the eGFR ( $\mathrm{ml} / \mathrm{min})$. Negative estimates for categorical variables imply that the reference category has a higher eGFR and for continuous variables that the eGFR decreases per unit of the continuous variables. For further model details cf. Supplementary Table 1. eGFR - estimated glomerular filtration rate; HCV - hepatitis C virus; BMI - body mass index; LTX - liver transplantation; Tac - tacrolimus.

Creatinine and eGFR are weight-dependent values. At the time of LTx (Table 1) and 12 months after LTx (fast metabolizers: $75.1 \pm 15.5 \mathrm{~kg}$; slow metabolizers: $78.3 \pm 17.3 \mathrm{~kg} ; \mathrm{P}=0.293$ ), the parameter weight showed no significant difference between the 2 groups. Age had a negative influence on the eGFR, resulting in a decrease of $1.4 \mathrm{ml} / \mathrm{min}$ per year of age. Females had $7.7 \mathrm{ml} / \mathrm{min}$ lower eGFR compared to males, and in HCVpositives the eGFR was $11.7 \mathrm{ml} / \mathrm{min}$ lower than in HCVnegatives. Nevertheless, both differences were not significantly different $(P>0.05)$. Neither BMI nor weight significantly affected renal function. Further details of the analysis, including the complete regression equation of the linear mixed model, can be found in Supplementary Table 1.

The analyses were repeated by using eGFR values obtained by the MDRD formula [21]. Mean MDRD eGFR values were considerably lower compared to CG eGFR values but showed a similar trend at 36-month follow-up (Supplementary Figure 1). MDRD eGFR values revealed significantly different slopes over time between the 2 Tac metabolism groups $(P=0.043)$. The main effect of Tac metabolism group revealed no significant influence on renal function $(P=0.204)$.

\section{Doses and trough blood concentrations}

The trough blood Tac concentrations were measured 1 month, 3 months, and 6 months after LTx. At 3 months and 6 months, slow metabolizers had significantly higher Tac concentrations (Table 5). Target trough concentrations were achieved 1 month and 3 months after LTx in both groups. After 6 months the median blood trough concentration of slow metabolizers $(8.1 \mathrm{ng} / \mathrm{mL})$ was slightly higher than the target range of 


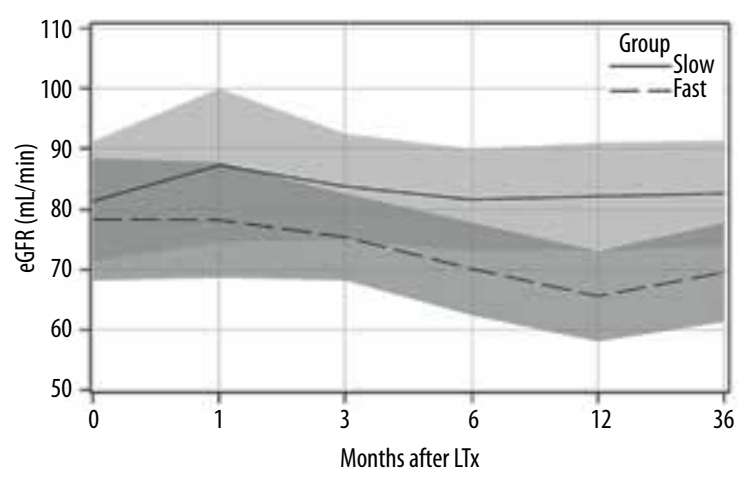

Figure 3. Estimated renal function measured by estimated glomerular filtration rate (Cockcroft-Gault eGFR, $\mathrm{mL}$ / min) after LTx. There was no noticeable difference between fast and slow tacrolimus metabolizers at LTx, or at 1 month or 3 months after LTx. After 6, 12, and 36 months, fast tacrolimus metabolizers had significantly more impaired renal function than slow metabolizers. Mean estimates and corresponding 95\% confidence intervals from the multivariable linear mixed model are plotted; overlapping areas are shown in dark grey.

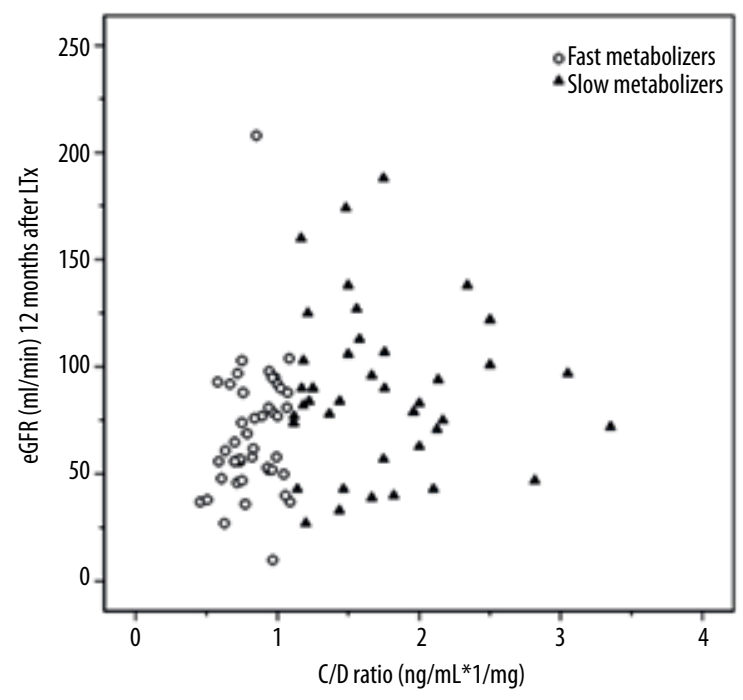

Figure 4. Scatterplot of tacrolimus (Tac) C/D ratio and eGFR values 12 months after LTx. The Spearman correlation coefficient showed no clear correlation between the 2 parameters $(r=0.311)$. Nevertheless, 12 months after LTx, fast Tac metabolizers revealed noticeably lower eGFR values as shown in the multivariate linear mixed model (Table 3).

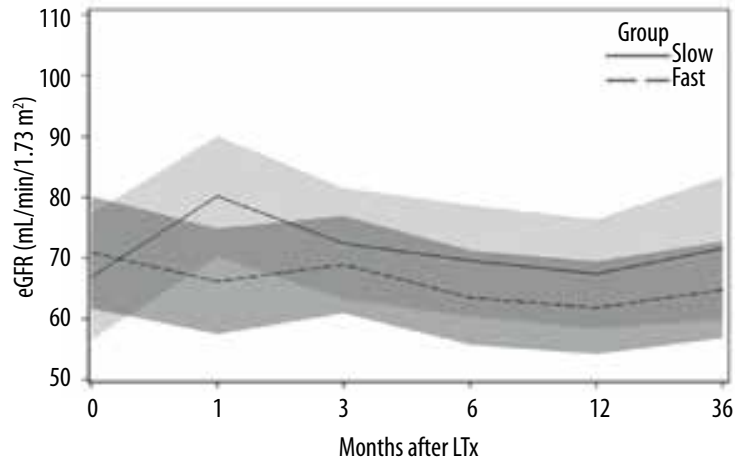

Supplementary Figure 1. Estimated renal function measured by estimated glomerular filtration rate (MDRD eGFR, $\mathrm{mL} / \mathrm{min} / 1.73 \mathrm{~m}^{2}$ ) after LTx.

4-8 ng/mL. The Tac doses of fast metabolizers were noticeably higher than slow metabolizers at all 3 time points, although the prednisolone doses were not noticeably different between the groups.

\section{Switch of immunosuppression regime}

A similar proportion of patients in both groups was changed to a different treatment (Table 6, P=1). The most common reason for changing was assumed $\mathrm{CNI}$ nephrotoxicity, with a significantly greater number of fast metabolizers $(P=0.027)$.

\section{Liver function tests}

Routine liver function tests were also performed (Table 7). There were no noticeable differences in serum ALT concentration or INR between the groups. Fast metabolizers were characterized by significantly lower serum bilirubin concentrations at 6 months, 12 months, and 36 months, although the median bilirubin concentration was broadly comparable in each group and within the normal laboratory range.

\section{Serious adverse events}

After 6 months had elapsed post-transplant, 1 patient (a fast metabolizer) lost transplant function because of hepatic steatosis (Table 6).

Twelve of the 115 patients included in the study died between months 6 and 36 (10.4\%, Table 6$)$. A greater proportion of slow metabolizers died, although the difference was not statistically significant (Table 6). The most common cause of death in the 115 patients included in the study was relapse of a hepatocellular carcinoma. 
Supplementary Table 1. Linear regression model equation.

\begin{tabular}{|c|c|c|c|c|c|}
\hline Fixed effects & & $\begin{array}{l}\text { Estimated } \\
\text { regression } \\
\text { coefficient }\end{array}$ & $\begin{array}{l}\text { Lower } 95 \% \\
\text { confidence limit }\end{array}$ & $\begin{array}{l}\text { Upper } 95 \% \\
\text { confidence limit }\end{array}$ & P-value \\
\hline Intercept & & 103.0 & 71.0 & 135.0 & $<0.001$ \\
\hline \multirow[t]{2}{*}{ Sex } & If female & -7.7 & -20.9 & 5.4 & 0.249 \\
\hline & If male & ref. & & & \\
\hline Age at LTx (per year) & & -1.4 & -1.8 & -1.1 & $<0.001$ \\
\hline Weight at LTx (per kg) & & 0.7 & -0.1 & 1.4 & 0.084 \\
\hline BMI (per kg/m²) & & 0.1 & -2.4 & 2.6 & 0.927 \\
\hline \multirow[t]{2}{*}{ HCV status } & If positiv & -11.7 & -23.8 & -0.3 & 0.107 \\
\hline & & ref. & & & \\
\hline \multirow[t]{2}{*}{ Tac metabolism group } & If slow & 13.0 & 2.2 & 23.8 & 0.018 \\
\hline & If fast & ref. & & & \\
\hline \multirow[t]{5}{*}{ Time point } & If at time of LTX & 8.8 & -1.9 & 19.5 & 0.107 \\
\hline & If 1 month & 8.7 & 0.0 & 17.3 & 0.049 \\
\hline & If 3 months & 5.8 & -0.3 & 12.0 & 0.061 \\
\hline & If 6 months & 0.6 & -5.6 & 6.7 & 0.851 \\
\hline & If 12 months & -4.0 & -9.2 & 1.3 & 0.137 \\
\hline \multirow[t]{6}{*}{$\begin{array}{l}\text { Tac metabolism group* } \\
\text { Time point }\end{array}$} & If slow and time of LTX & -10.1 & -24.6 & 4.5 & 0.174 \\
\hline & If slow and 1 month & -4.0 & -19.6 & 11.6 & 0.616 \\
\hline & If slow and 3 months & -4.7 & -15.3 & 6.0 & 0.390 \\
\hline & If slow and 6 months & -1.6 & -12.0 & 8.8 & 0.761 \\
\hline & If slow and 12 months & 3.5 & -5.6 & 12.6 & 0.447 \\
\hline & If fast or 36 months & ref. & & & \\
\hline
\end{tabular}

Reference category (=Intercept): sex=male, age=0, weight=0, BMI=0, HCV status=neg., Tac metabolism group=fast, time point $=36$ months. Independent variables were renal function group, weight, age at LTX, gender, HCV status, BMI, time point and the interaction between renal function group and time point. The repeated measurements of eGFR values were modeled using a first-order antedependence covariance structure (ANTE(1)) with patient as subject and time point as repeated variable. For example, a patient (sex=male, age $=50$ years, weight $=80 \mathrm{~kg}, \mathrm{BMI}=22 \mathrm{~kg} / \mathrm{m}^{2}, \mathrm{HCV}$ status=pos., Tac metabolism group=slow, time point $=1 \mathrm{month}$ ) has an expected eGFR value of: $103+0+\left(-1.4^{\star} 50\right)+\left(0.7^{\star} 80\right)+\left(0.1^{\star} 22\right)-11.7+(13+8.7-4.0)=97.7 \mathrm{ml} / \mathrm{min}$.

\section{Discussion}

Our findings support the hypothesis that the Tac metabolism rate of liver allograft recipients is associated with renal function. We found that a C/D ratio of $<1.09$, corresponding to fast metabolizers of Tac, was associated with greater renal impairment after LTX in a 36-month follow-up period compared with a $C / D$ ratio $\geq 1.09$.
Demographic characteristics, such as sex and age, are known to have an impact on Tac metabolism [6], and many drugs may cause changes in the Tac metabolism rate, particularly those that interact with CYP3A4 and CYP3A5 [8]. Compared with other studies in the literature, we found that higher Tac doses were required when higher corticosteroid doses were administered in the early months after LTx $[22,23]$. 
Table 5. Doses and blood trough tacrolimus concentrations.

\begin{tabular}{|c|c|c|c|}
\hline & $\begin{array}{l}\text { Fast metabolizers } \\
\qquad(n=58)\end{array}$ & $\begin{array}{l}\text { Slow metabolizers } \\
\qquad(n=57)\end{array}$ & P-value \\
\hline \multicolumn{4}{|c|}{ Tacrolimus mean trough level (ng/ml) } \\
\hline After 1 month & $8.6(4.7-13.5)$ & $9.2(7.0-14.4)$ & $0.0674^{*}$ \\
\hline After 3 months & $8.0(5.4-15.8)$ & $9.0(4.5-22.7)$ & $0.0069^{*}$ \\
\hline After 6 months & $7.5(4.3-13.9)$ & $8.1(5.9-16.9)$ & $0.0086^{*}$ \\
\hline \multicolumn{4}{|c|}{ Tacrolimus daily dose (mg) } \\
\hline After 1 month & $13.1 \pm 4.2$ & $8.2 \pm 2.8$ & $<0.0001^{\star *}$ \\
\hline After 3 months & $11.0 \pm 3.6$ & $7.0 \pm 2.8$ & $<0.0001^{\star *}$ \\
\hline After 6 months & $9.7 \pm 3.0$ & $5.5 \pm 2.1$ & $<0.0001^{\star \star}$ \\
\hline \multicolumn{4}{|c|}{ Prednisolone daily dose (mg) } \\
\hline After 1 month & $17.2 \pm 7.1$ & $14.9 \pm 5.4$ & $0.0465^{\star *}$ \\
\hline After 3 months & $10.1 \pm 5.8$ & $9.6 \pm 3.7$ & $0.620^{* *}$ \\
\hline After 6 months & $7.1 \pm 4.1$ & $6.5 \pm 2.4$ & $0.391^{\star \star}$ \\
\hline
\end{tabular}

* P-value from Mann-Whitney-U-test; ${ }^{* *}$ P-value from the t-test.

Table 6. Change in immunosuppression regime, death and loss of function.

\begin{tabular}{|c|c|c|c|}
\hline & $\begin{array}{l}\text { Fast metabolizers } \\
\qquad(n=58)\end{array}$ & $\begin{array}{c}\text { Slow metabolizers } \\
\qquad(n=57)\end{array}$ & P-value \\
\hline Change in IS & $34(58.6 \%)$ & $33(57.9 \%)$ & 1 \\
\hline CNI nephrotoxicity & 19 (32.8\%) & $8(14.0 \%)$ & 0.027 \\
\hline Compliance & $9(15.5 \%)$ & $11(19.3 \%)$ & 0.630 \\
\hline Malignancy & 0 & $5(8.8 \%)$ & 0.027 \\
\hline Tumor anamnesis & $1(1.7 \%)$ & $2(3.5 \%)$ & - \\
\hline Adverse Events & $5(9 \%)$ & $4(7.0 \%)$ & 1 \\
\hline Infections & 0 & $2(3.5 \%)$ & 0.243 \\
\hline Death & $4(7 \%)$ & $8(14.0 \%)$ & 0.238 \\
\hline Malignancy & 0 & $4(7.0 \%)$ & - \\
\hline Multiorgan failure & $1(1.7 \%)$ & $3(5.3 \%)$ & - \\
\hline Hemorrhagic shock & $1(1.7 \%)$ & 0 & - \\
\hline Cerebral insult & 0 & $1(1.8 \%)$ & - \\
\hline Infection & $1(1.7 \%)$ & 0 & - \\
\hline Unknown & $1(1.7 \%)$ & 0 & - \\
\hline Onset of dialysis & $3(5.2 \%)$ & 0 & 0.083 \\
\hline Loss of liver function & $1(1.7 \%)$ & 0 & - \\
\hline
\end{tabular}

IS - immunosuppression; CNI - calcineurin inhibitor. P-values from Fisher's exact test. 
Table 7. Liver function tests.

\begin{tabular}{|c|c|c|c|}
\hline & $\begin{array}{l}\text { Fast metabolizers } \\
\qquad(n=58)\end{array}$ & $\begin{array}{l}\text { Slow metabolizers } \\
\qquad(n=57)\end{array}$ & P-value \\
\hline \multicolumn{4}{|l|}{ Bilirubin } \\
\hline At LTx & $4.4(0.3-48.0)$ & $2.3(0.3-39.5)$ & 0.384 \\
\hline 6 months & $0.5(0.2-8.4)$ & $0.6(0.3-1.8)$ & 0.0043 \\
\hline 12 months & $0.5(0.2-4.0)$ & $0.6(0.4-1.5)$ & 0.024 \\
\hline 36 months & $0.5(0.2-0.8)$ & $0.7(0.2-2.9)$ & 0.0006 \\
\hline \multicolumn{4}{|l|}{ ALT } \\
\hline At LTx & $113(7-1,798)$ & $217(11-3,397)$ & 0.127 \\
\hline 6 months & $25(5-170)$ & $27(5-321)$ & 0.161 \\
\hline 12 months & $25(6-64)$ & $26(5-340)$ & 0.268 \\
\hline 36 months & $22(11-108)$ & $18(9-98)$ & 0.616 \\
\hline \multicolumn{4}{|l|}{ INR } \\
\hline At LTx & $1.2(0.8-2.6)$ & $1.3(0.9-5.7)$ & 0.790 \\
\hline 6 months & $1.0(0.9-2.9)$ & $1.0(0.9-1.3)$ & 0.883 \\
\hline 12 months & $1.0(0.9-3)$. & $1.0(0.9-1.1)$ & 0.915 \\
\hline 36 months & $1.0(0.9-1.7)$ & $1.0(0.8-1.2)$ & 0.321 \\
\hline
\end{tabular}

LTX - liver transplantation; ALT - alanine transaminase; INR - international normalized ratio.

Many genetic variables are also known to influence Tac metabolism in RTx and LTx recipients [6,24-26]. Interestingly, it has not been possible to show incontrovertibly that pharmacogenetic differences between patients have a clinically important impact on the efficacy or toxicity of Tac [26]. Furthermore, genetic tests are expensive, take a long time to process, and require an additional blood test for the patient. The large number of factors that influence Tac metabolism mean that predicting the required dose accurately can be very difficult [27]. Therefore, a simple tool to predict the risk of CNI nephrotoxicity would have substantial clinical utility.

We recently reported that fast Tac metabolism with a C/D ratio $<1.05$ was associated with impaired renal function after RTx [17], a finding that agrees with the results of this study of a cohort of LTx recipients, in which a similar C/D ratio of $<1.09$ characterized patients as fast metabolizers. Fast metabolizers also exhibited noticeably lower eGFRs than slow metabolizers. Given that creatinine and eGFR are weight-dependent values, these parameters may be overestimated in patients with liver disease [28]. In the cohort of this study, at the time of LTx and 12 months later, no noticeable differences in weight were found between the 2 groups.

CNI nephrotoxicity is the most plausible cause of renal impairment after LTx $[17,29,30]$. There have been several reports that there is a dose-dependent relationship between Tac and CNI nephrotoxicity $[2,3]$. In our cohort, fast metabolizers needed noticeably higher daily Tac doses than slow metabolizers during the first 6 months. As Tac target trough concentrations were not significantly different between the groups after 6 months, the Tac dose may not influence renal function by its trough blood concentration alone. Kuypers et al. reported an association between high daily Tac requirements and histologically proven CNI nephrotoxicity after RTx [31]. A possible explanation for the impaired renal function seen in fast metabolizers could be an elevated - and therefore more nephrotoxic - peak Tac concentration in the first hours after administration [5,32]. Especially in a subgroup of mainly slow metabolizers that retain an eGFR $>100 \mathrm{ml} / \mathrm{min}$, a low Tac peak concentration might be advantageous.

Primarily, the CG equation was used for estimation of the GFR in this study due to a mean GFR $>60 \mathrm{ml} / \mathrm{min}$ [20]. Although established in many previous studies, the CG equation has several limitations and is mainly influenced by age, body weight, and BMI [33]. More modern equations like MDRD and CKDEPI seem to give the best estimation of GFR but are more influenced by the GFR itself $[34,35]$. Especially in the GFR-range $>60 \mathrm{ml} / \mathrm{min} / 1.73 \mathrm{~m}^{2}$, the latter equations reveal a larger bias compared to the CG equation $[33,36]$. This might explain differences in association between $C / D$ ratio and renal function. Nevertheless, by using the MDRD equation, the 2 metabolism groups also showed statistically significant differences in renal function at 36-month follow-up. 
We also found that a greater proportion of fast metabolizers than slow metabolizers were switched from Tac due to presumed CNI nephrotoxicity. Early introduction of everolimus together with a reduced trough Tac concentration reportedly achieves statistically and clinically significant benefits for renal function 2 years after LTx [37].

In this study the median follow-up liver parameters were in the normal range. This suggests that differences in hepatic function as a cause for an impaired renal function in the group of fast Tac metabolizers is very unlikely. Structural parenchymal changes in the liver mean that older patients metabolize CNIs more slowly [38]. Our linear mixed model demonstrated that age showed a highly significantly association with renal function after LTx, but age at LTx did not differ significantly between the 2 Tac metabolism groups. We also found that female sex and positive HCV status had negative influences on renal function after LTx, which is in broad agreement with a study from Australia, which reported that female sex and HCV infection were risk factors for the development of severe chronic kidney disease in LTx recipients [39]. The majority of serious adverse events, such as death or loss of liver function, occurred within the first 6 months after LTx, but because we first analyzed the C/D ratio at 6 months to avoid the potentially confounding influence of prednisolone, we cannot draw any conclusions about the impact of Tac metabolism rate on these events.

\section{References:}

1. McAlister VC, Haddad E, Renouf E et al: Cyclosporin versus tacrolimus as primary immunosuppressant after liver transplantation: a meta-analysis. Am J Transplant, 2006; 6: 1578-85

2. Boudjema K, Camus C, Saliba F et al: Reduced-dose tacrolimus with mycophenolate mofetil vs. standard-dose tacrolimus in liver transplantation: a randomized study. Am J Transplant, 2011; 11: 965-76

3. Neuberger JM, Mamelok RD, Neuhaus $P$ et al: Delayed introduction of reduced-dose tacrolimus, and renal function in liver transplantation: the 'ReSpECT' study. Am J Transplant, 2009; 9: 327-36

4. Jacobson PA, Schladt D, Israni A et al: Genetic and clinical determinants of early, acute calcineurin inhibitor-related nephrotoxicity: results from a kidney transplant consortium. Transplantation, 2012; 93: 624-31

5. Tsuchiya T, Ishida H, Tanabe $\mathrm{T}$ et al: Comparison of pharmacokinetics and pathology for low-dose tacrolimus once-daily and twice-daily in living kidney transplantation: prospective trial in once-daily versus twice-daily tacrolimus. Transplantation, 2013; 96: 198-204

6. Stratta $P$, Quaglia M, Cena T et al: The interactions of age, sex, body mass index, genetics, and steroid weight-based doses on tacrolimus dosing requirement after adult kidney transplantation. Eur J Clin Pharmacol, 2012; 68: $671-80$

7. Gijsen V, Mital S, van Schaik RH et al: Age and CYP3A5 genotype affect tacrolimus dosing requirements after transplant in pediatric heart recipients. J Heart Lung Transplant, 2011; 30: 1352-59

8. Kuypers DR: Influence of interactions between immunosuppressive drugs on therapeutic drug monitoring. Ann Transplant, 2008; 13(3): 11-18

9. van Duijnhoven EM, Boots JM, Christiaans MH et al: Increase in tacrolimus trough levels after steroid withdrawal. Transpl Int, 2003; 16: 721-25
Our study has some other limitations. First, data were collected retrospectively. Second, it was a single-center study of a population that was mainly of Western European descent, meaning that it is difficult to generalize our findings to other ethnic groups with different genetic characteristics. Furthermore, many patients met 1 or more exclusion criteria during the early months after LTx and were thus not included in the analysis; therefore, conclusions only apply to patients who met the inclusion criteria. A substantial proportion also required several switches of immunosuppression regimen. This combination of factors means that we can only provide data at 36-month follow-up. Due to the study design, we cannot determine predictive value of the C/D ratio in renal function. Thus, prospective, controlled, multicenter studies are needed to establish the role of the C/D ratio as a clinical tool for identifying patients at risk of $\mathrm{CNI}$ nephrotoxicity. The implementation of the Tac peak concentration early after administration should offer further information in this context.

\section{Conclusions}

Mitigating risk is fundamental to improving graft survival, preserving renal function, and ensuring patient safety. Our findings show an association between a Tac C/D ratio $<1.09 \mathrm{ng} / \mathrm{mL}^{*} 1 / \mathrm{mg}$ and renal dysfunction. Prospective, controlled trials are needed to establish C/D ratio as a risk factor for renal impairment.

10. Uesugi M, Masuda S, Katsura T et al: Effect of intestinal CYP3A5 on postoperative tacrolimus trough levels in living-donor liver transplant recipients. Pharmacogenet Genomics, 2006; 16: 119-27

11. Sato K, Amada N, Sato T et al: Severe elevations of FK506 blood concentration due to diarrhea in renal transplant recipients. Clin Transplant, 2004; 18: 585-90

12. Joy MS, Hogan SL, Thompson BD et al: Cytochrome P450 $3 \mathrm{~A} 5$ expression in the kidneys of patients with calcineurin inhibitor nephrotoxicity. Nephrol Dial Transplant, 2007; 22: 1963-68

13. Sattler M, Guengerich FP, Yun CH et al: Cytochrome P-450 3A enzymes are responsible for biotransformation of FK506 and rapamycin in man and rat. Drug Metab Dispos, 1992; 20: 753-61

14. Kuehl P, Zhang J, Lin $Y$ et al: Sequence diversity in CYP3A promoters and characterization of the genetic basis of polymorphic CYP3A5 expression. Nat Genet, 2001; 27: 383-91

15. Masuda S, Inui K: An up-date review on individualized dosage adjustment of calcineurin inhibitors in organ transplant patients. Pharmacol Ther, 2006; 112: 184-98

16. Yu S, Wu L, Jin J et al: Influence of CYP3A5 gene polymorphisms of dono rather than recipient to tacrolimus individual dose requirement in liver transplantation. Transplantation, 2006; 81: 46-51

17. Tholking G, Fortmann C, Koch $\mathrm{R}$ et al: The tacrolimus metabolism rate influences renal function after kidney transplantation. PloS One, 2014; 9: e111128

18. Goto $M$, Masuda S, Kiuchi T et al: CYP3A5*1-carrying graft liver reduces the concentration/oral dose ratio of tacrolimus in recipients of living-donor liver transplantation. Pharmacogenetics, 2004; 14: 471-78 
19. Ji E, Choi L, Suh KS et al: Combinational effect of intestinal and hepatic CYP3A5 genotypes on tacrolimus pharmacokinetics in recipients of living donor liver transplantation. Transplantation, 2012; 94: 866-72

20. Cockcroft DW, Gault MH: Prediction of creatinine clearance from serum creatinine. Nephron, 1976; 16: 31-41

21. Levy AS BJ, Lewis JB, Greene T et al. for the Modification of Diet in Renal Disease Group: A more accurate method to estimate glomerular filtration rate from serum creatinine: a new prediction equation. Ann Intern Med, 1999; 130: 461-70

22. Shimada T, Terada A, Yokogawa $\mathrm{K}$ et al: Lowered blood concentration of tacrolimus and its recovery with changes in expression of CYP3A and P-glycoprotein after high-dose steroid therapy. Transplantation, 2002; 74: 1419-24

23. Pou L, Brunet $M$, Andres I et al: Influence of posttransplant time on dose and concentration of tacrolimus in liver transplant patients. Transpl Int, 1998; 11(Suppl.1): S270-71

24. Kuypers DR, de Jonge $H$, Naesens $M$ et al: CYP3A5 and CYP3A4 but not MDR1 single-nucleotide polymorphisms determine long-term tacrolimus disposition and drug-related nephrotoxicity in renal recipients. Clin Pharmacol Ther, 2007; 82: 711-25

25. Li CJ, Li L, Lin L et al: Impact of the CYP3A5, CYP3A4, COMT, IL-10 and POR genetic polymorphisms on tacrolimus metabolism in Chinese renal transplant recipients. PloS One, 2014; 9: e86206

26. Provenzani A, Santeusanio A, Mathis E et al: Pharmacogenetic considerations for optimizing tacrolimus dosing in liver and kidney transplant patients. World J Gastroenterol, 2013; 19: 9156-73

27. Evans WE, McLeod HL: Pharmacogenomics - drug disposition, drug targets, and side effects. N Engl J Med, 2003; 348: 538-49

28. Beben T, Rifkin DE: GFR estimating equations and liver disease. Adv Chronic Kidney Dis, 2015; 22: 337-42
29. Fabrizi F, Dixit V, Martin P, Messa P: Chronic kidney disease after liver transplantation: Recent evidence. Int J Artif Organs, 2010; 33: 803-11

30. Ziolkowski J, Paczek L, Senatorski G et al: Renal function after liver transplantation: calcineurin inhibitor nephrotoxicity. Transplantat Proc, 2003; 35: 2307-9

31. Kuypers DR, Naesens $M$, de Jonge $H$ et al: Tacrolimus dose requirements and CYP3A5 genotype and the development of calcineurin inhibitor-associated nephrotoxicity in renal allograft recipients. Ther Drug Monit, 2010; 32: 394-404

32. Kimikawa M, Kamoya K, Toma H, Teraoka S: Effective oral administration of tacrolimus in renal transplant recipients. Clin Transplant, 2001; 15: 324-29

33. Michels WM, Grootendorst DC, Verduijn $M$ et al: Performance of the Cockcroft-Gault, MDRD, and new CKD-EPI formulas in relation to GFR, age, and body size. Clin J Am Soc Nephrol, 2010; 5: 1003-9

34. Levey AS, Stevens LA, Schmid $\mathrm{CH}$ et al: A new equation to estimate glomerular filtration rate. Ann Intern Med, 2009; 150: 604-12

35. Levey AS, Coresh J, Greene T et al: Using standardized serum creatinine values in the modification of diet in renal disease study equation for estimating glomerular filtration rate. Ann Intern Med, 2006; 145: 247-54

36. Myers GL, Miller WG, Coresh J et al: Recommendations for improving serum creatinine measurement: a report from the Laboratory Working Group of the National Kidney Disease Education Program. Clin Chem, 2006; 52: 5-18

37. Saliba F, De Simone P, Nevens F et al: Renal function at two years in liver transplant patients receiving everolimus: results of a randomized, multicenter study. Am J Transplant, 2013; 13: 1734-45

38. McLean AJ, Le Couteur DG: Aging biology and geriatric clinical pharmacology. Pharmacol Rev, 2004; 56: 163-84

39. Ramachandran J, Juneja R, John L et al: Chronic kidney disease following liver transplantation: a South Australian experience. Transplant Proc, 2010; 42: 3644-46 